\title{
Comer en el aquelarre: Entre lo sublime y lo repugnante. Una perspectiva trasatlántica
}

\author{
Eating at the Witches' Sabbath: Between the Sublime \\ and the Abhorrent. A Transatlantic Perspective
}

\author{
Gerardo Fernández Juárez \\ Universidad de Castilla-La Mancha. Toledo
}

\section{RESUMEN}

Del complejo escenario que las juntas diabólicas o aquelarres configuran, este artículo se centra en las comidas y sus expresiones sensibles según se desprende de los relatos inquisitoriales, con especial énfasis en el proceso de las brujas de Zugarramurdi, cuyo Auto de Fe, celebrado en Noviembre de 1610 ha cumplido los 400 años. La tipología de viandas consumidas en el aquelarre y sus expresiones culinarias, según las aportaciones de los intelectuales de la época, reflejan una etnografía inventada que configura expresiones sociales inversas en función de una gastronomía nefanda y abominable, algunas de cuyas características pueden rastrearse en el continente americano a través de los expedientes inquisitoriales y de extirpación de idolatrías.

Palabras clave: Aquelarre, Brujería, Canibalismo, Idolatría, Gastronomía nefanda.

\section{SUMMARY}

Within the very complex performance of a witches' Sabbath, this article focuses on their meals and its different expressions according to inquisitorial records, while putting great emphasis on the trial of the witches of Zugarramurdi, whose 'act of faith', held in November 1610, is now about 400 years old. According to intellectuals at the time, the typology of the food consumed as well as its culinary forms seems to reflect an invented ethnography which implies reverse social expressions regarding loathsome gastronomy. Some features of this abhorrent gastronomy can be tracked on the American continent through inquisitorial records and the extirpation of idolatry.

Key words: Witches' Sabbath, Witchcraft, Cannibalism, Idolatry, Abhorrent Gastronomy.

Hace más de cuatrocientos años del Auto de Fe de Logroño (6 y 7 de Noviembre de 1610), que consumó el juicio sumarísimo de numerosos vecinos de las comarcas de Zugarramurdi y Urdax en las montañas navarras. Como es bien sabido, ocasionó la condena de once personas a morir quemadas en la hoguera, acusadas de practicar la brujería; cinco fueron quemadas en efigie y carbonizados sus restos mortales, puesto que ya habían fallecido anteriormente a la ejecución, y seis fueron quemadas vivas 
ante su negativa a aceptar los cargos $^{1}$. La crónica que sobre los hechos publica Mongastón en 1611 generaliza el conocimiento de los mismos y contribuye a la extensión del modelo que sólo finalizará en las montañas "vasco navarras" tras los sucesivos edictos de gracia y las firmes recomendaciones de la Suprema después de oir las razones de los jueces inquisitoriales que intervinieron en el Auto de Fe. El bando "crédulo" que afirmaba la naturaleza real de los hechos descritos por los encausados, bajo coacción en muchos casos, encabezado por los inquisidores Juan del Valle y Alonso Becerra, y el bando racional, completamente escéptico frente a los relatos inauditos de los afectados, comandado por el inquisidor Alonso de Salazar y Frías con el apoyo de otros actores que intervinieron en la indagación de los hechos, como el Obispo de Pamplona, se enzarzaron en lo que Heningssen denomina "la guerra de las brujas", enviando sendas memorias y argumentos al Consejo de la Suprema, quien en 1614 otorga las recomendaciones a tener en cuenta a partir de entonces, reclamando discreción y prudencia en materia de brujas ${ }^{2}$.

El aquelarre o junta de brujas constituye una de las expresiones señeras del proceso de Zugarramurdi, incorporando los rasgos que acentúan la polémica intelectual sobre la verosimilitud, realidad o ensueño de lo que las brujas cuentan y realizan en sus juntas y conciliábulos: ungüentos y vuelos al lugar de reunión, transformismo animal, homenaje al diablo bajo forma de cabrón, beso en el culo, bailes acrobáticos, banquetes nefandos, canibalismo, infanticidio, misas negras... etc. Todos ellos ingredientes que forman parte de lo que Levack denomina principio acumulativo de brujería (Levack 1995) y que son responsables de la psicosis social que afecta a las poblaciones en cuanto se narran desde los púlpitos en los sermones de las parroquias de aldea, o en la propia realización de los Autos de Fe en donde se leen públicamente los "crímenes" y felonías de los que se acusaba a los encartados. De hecho el proceso de Zugarramurdi parece consecuencia de la crisis social que la feroz represión de la brujería ocasiona en el Pays de Labourd por parte del temible juez de Burdeos Pierre de Lancre, en $1609^{3}$.

Estos elementos integrantes del modelo de aquelarre pirenaico en la Edad Moderna, constituyen motivos recurrentes a lo largo de la historia de la humanidad en cuanto un nuevo grupo social pone en jaque la legitimidad política, económica o religiosa

${ }^{1}$ La bibliografía sobre el caso de Zugarramurdi resulta muy extensa (Caro Baroja 1961 y 1975 ; Fernández Nieto 1989; Henningsen 1983; Henningsen 2004; Idoate 1972; Marcos Casquero y Riesco Alvarez 1997). Igualmente cabe destacar las publicaciones efectuadas con motivo de la celebración de los cuatrocientos años del Auto de Fe de Logroño (Usunáriz 2012; Ramalle Gómara y Azurmendi Inchausti 2010). Merece la pena resaltar la polémica entre Hennigsen (2012) y Azurmendi (2012) en torno al término aquelarre y su creación erudita.

${ }^{2}$ Las recomendaciones están inspiradas en las conclusiones de Alonso de Salazar y Frías tras su densa y prolífica visita a los lugares afectados: "Sólo hubo brujas y brujos cuando se empezó a hablar y escribir de ellos" (Heningsen 1983).

3 Gustav Hennigssen matiza de una forma acertada la diferencia entre lo que son las creencias en brujería de corte tradicional frente a la "brujomanía" que es consecuencia de la sesuda reflexión de los intelectuales modernistas de la época. El fenómeno de la "brujomanía" prende en las masas populares, cuando las reflexiones eruditas, sus criterios y figuras referentes al fenómeno de la brujería, sobrepasan los linderos de la intelectualidad para penetrar desaprensivamente en las mentalidades e imaginarios populares, generando pavores y psicosis sociales de sorprendente magnitud (Hennigsen 2010). 
del grupo hegemónico de referencia, como ha mostrado Cohn (1997 [1976]). Resabios del aquelarre encontramos en prácticas chamánicas relacionadas con cultos de la fertilidad, al estilo de la célebre hipótesis de Margared Murray (1978), vinculadas con ceremonias de homenaje a los antepasados en el Friul, analizadas por Ginzburg (2003; 2011), en su monografía sobre los Benandanti.

Del complejo dominio de expresiones que el aquelarre muestra, quiero centrarme en aquellos rasgos que acreditan una relevancia social más significativa del fenómeno en su expresión festiva inversa, a través de sus peculiares comidas y banquetes ${ }^{4}$, siempre según las informaciones de los participantes en dichas reuniones a través de los expedientes inquisitoriales que protagonizan. Todos ellos constituyen rasgos plausibles del formato del llamado aquelarre como carnavalada que posiblemente algunos usaron justificándose en el mito social constituido por la brujería y sus expresiones sensibles.

\section{COMER, BEBER, HOLGAR}

Una de las razones que esgrimían los brujos y brujas de Zugarramurdi y Urdax ${ }^{5}$ para afiliarse a la secta brujeril era la posibilidad de disfrutar de buenos banquetes en el aquelarre. Comer, beber y holgar fácilmente constituían expresiones de placer y ocio difícilmente satisfechas en las montañas navarras de la época:

Johanes de Goyburu, de hedad de 36 años, nº 10, fol.44, dize que siendo de hedad de 14, estando un dia como a la una de la tarde / guardando obejas, Miguel de Goyburu, su padre, le dixo: Sabete, hijo que soy bruxo, y que tu tambien lo as de ser, y beras como nos holgaremos y bailaremos y comeremos bien (Idoate 1972: 48).

¿Qué viandas, especies y condimentos constituyen ese banquete suculento? ¿Qué estrategias culinarias consiguen los brujos para sazonar convenientemente los productos y obtener texturas, aromas y sabores gustosos? Escuchemos sus declaraciones:

Confiesan los bruxos que cenan en los aquelarres muchas noches, en especial las bisperas de fiestas prinçipales y quando se an muerto algunos bruxos. Y que puesta la mesa con manteles negros, comen un pan negro, cebollas, frutas, carne y otras cosas, y beuen bino. $\mathrm{Y}$ que las carnes que comen, son de personas difuntas que desentierran y sacan de los çementerios, y en espeçial todos los cuerpos de los que an sido bruxos. Y muchos de-

\footnotetext{
${ }^{4}$ Además de las comidas, las danzas, interpretaciones musicales y composiciones coreicas que protagonizan los participantes, así como las relaciones sexuales que incentivan la reunión poco antes de dar por terminado el conciliábulo, serán consideradas en parte a lo largo del análisis al constituir expresiones que habitualmente refuerzan, junto a la comida, el tejido social en las comunidades humanas en sus manifestaciones habituales.

${ }^{5}$ Las referencias sobre el caso de Zugarramurdi están recogidas del texto que elaboraron los crédulos inquisidores Juan del Valle y Alonso Becerra y que remitieron a la Suprema con intención de convencerles de la realidad de los actos allí expuestos (Idoate 1972). Los detalles y la amplia casuística, con ejemplos que emanan igualmente del relato de Mongastón, hacen de este documento una referencia "quasi etnográfica" importante sobre la que los inquisidores Valle y Becerra trataron de argumentar sus razones en defensa del valor real de lo que los encausados dicen. En este sentido, si bien las propuestas sobre el aquelarre responden a las obsesiones de los eruditos, hay que reconocer que prendieron con rapidez en las clases populares.
} 
claran que les sauen muy bien las cosas que alli comen, y otros dizen que les causan asco y se les rebuelbe el estomago, y las bomitan y truecan en sus casas. Y que el dia siguiente, regueldan al sabor de las cosas que çenaron la noche preçedente y sienten cargados los estomagos, de lo qual solo se haze consideraçion en este acto, porque con esto se comprueua auer sido ciertas y verdaderas las dichas cenas. Y para comprouacion, proponen las confessiones siguientes:

Maria de Çozaya, de hedad de 80 años, n.ำ 19, fol. 88, dize como ella y los demás bruxos çenauan en el aquelarre pan, queso, bino y ceuolla, y quando se ofreçia ocasíon de la muerte de algún bruxo, desenterraban el cuerpo y le lleuauan al aquelarre y le despedaçauan. Y parte asaban y parte / coçian y parte quedaua crudo y lo cenaban, y que algunas bezes, la cena y bebida del aquelarre le rrebolbia a esta el estomago, y quando boluia a casa, lo trocaua, y otro dia lo echaua de ber en la parte donde lo auia bomitado. Y quando esto le suçedia, estaua ocho o diez dias en cama mal dispuesta. Catalina de Porto, de hedad de 60 años, n.. 34, fol. 13, dize que, muchas bezes, lo que çenaua en el aquelarre le rremobia el estomago y despues lo bolbia, quando llegaua a casa, algunas bezes, otro dia por la mañana. Petri del Espinal, de hedad de 70 años, no 37, fol 21 dize que en el aquelarre acostumbrauan cenar los bruxos los cuerpos de otros bruxos y aun de otros difuntos que no lo son. Y que le sucedio algunas bezes, que el estomago no podia sufrir lo que auia çenado en el aquelarre, por ser carne hedionda asquerosa, y en su casa hazia bomitar de la dicha cena, con que descargaua el estomago. Thomasa de Yturen, de hedad de 80 años, n⿳⺈ 38, fol.17 dize que las cenas del aquelarre muchas bezes le hazian daño la rreboluian el estomago, y otro dia las bomitaua (Idoate 1972: 134).

Es decir, podemos observar la presencia de productos alimenticios característicos de la época en el ámbito rural navarro, como son el queso, las cebollas, frutas, carne, vino y pan $^{6}$. La introducción de los inquisidores carga las tintas sobre ciertos valores cromáticos presentes en el banquete, según su criterio, como es el caso del pan negro $^{7}$ y los manteles del mismo color; circunstancia que avisa sobre algo anómalo con respecto a los colores predominantes en los banquetes festivos, el negro muestra un rasgo inverso relacionado con la presencia del diablo entre los comensales.

Francisco Bertol, de 32 años, $n^{\circ}$ 73, fol. 41, dize que en el aquelarre çenauan sobre unos manteles negros que tendian en el suelo y quel demonio estaua a la cauecera. Y sentados con el en el lugar mas preeminente, los clerigos, y luego, tras de ellos, los bruxos mas privados, y todos los demas se sentauan en el suelo. Y en la mesa se ponia un pan negro de mal sabor y carne de los cuerpos de los difuntos, que sacauan de las sepulturas. Y dexando en ellas las caueças y tripas con las mortajas, lleuauan lo demas al aquelarre y los despedazauan y comian asados y crudos y cocidos, y bebían bino, que no era bueno. Y quando la carne hera bieja y estaua pasada, le rreboluia a este el estomago y otro dia tenia grandes ascos, de manera que benia a bomitar lo que habia comido en el aquelarre (Idoate 1972: 136).

${ }^{6}$ En el modelo de aquelarre que se desplaza a América en el proceso colonial se aprecia la inclusión de productos de la tierra y elaboraciones específicas de los brujos y brujas, caso de los ajiacos y del cuscus de los afroamericanos de Cartagena de Indias, o las tortas de maíz en el dominio andino.

${ }^{7}$ En algunas juntas de brujos se incide especialmente en la ausencia de pan, como representación de Dios en la Eucaristía. Por su parte, el "pan negro" es una alegoría inversa y por tanto asociada a la presencia en el banquete del demonio. Al respecto documenta Lancre (2004 [1612]: 168) un relato edificante que sitúa en Limoges en 1609 donde un panadero consiguió evitar el maleficio sobre sus panes, que resultaban inexorablemente negros, introduciendo un agnusdei de cera en la masa antes de ser horneada. 
El banquete formal del aquelarre presenta aspectos diferenciados que marcan la posición jerárquica de los comensales. En unos casos los invitados se disponen en torno a una mesa alzada, sentados con las viandas a la vista; en otros, adquiere la apariencia festiva de lo que hoy denominaríamos "picnic" con los manteles y comensales en el suelo, pero con una marcada posición de asimetría social destacando la figura del diablo y sus servidores predilectos que comen sentados.

La reunión se convoca la víspera de las principales fiestas del calendario cristiano o bien tras la muerte de algún brujo o bruja. La carne procede de los cuerpos exhumados de brujos y brujas difuntos que se llevan al aquelarre, fruto de una necrofagia irredenta de la que se acusa a los brujos. Parece que difuntos e infantes constituyen objeto especial del canibalismo de los comensales agasajados en el aquelarre. Las carnes se dividen en tres partes que se comen respectivamente crudas, asadas y cocidas ${ }^{8}$. La crónica de Mongastón ofrece detalles sobre esta taxonomía culinaria, algunas vísceras y menudillos se ingieren crudos, de hecho constituyen una verdadera golosina para el demonio (Marcos y Riesco 1997: 176), los huesos largos se cuecen hasta quedar reblandecidos y los tejidos corporales principales se asan, incluso en asaderos portátiles que los brujos describen asiduamente. Esta versatilidad culinaria — asado, cocido y crudo- haría las delicias, si se permite la expresión, de los antropólogos de la alimentación estableciendo su posición liminal entre la extrema socialización de las viandas cocidas blandas y articuladas en el plato y el huraño aislamiento social de los manjares crudos, emparentados con la naturaleza. Obviamente el hecho de que se trate de procesos de canibalismo (endocanibalismo en el caso del consumo de los cuerpos de los brujos difuntos), invierte los vínculos sociales que la comida habitualmente permite expresar ${ }^{9}$. Ya Lévi-Strauss concedía una relevancia doméstica a los platos hervidos o cocidos frente a los asados especialmente indicados para el agasajo del foráneo no perteneciente al cuerpo social de los anfitriones culinarios (Arens 1981: 24).

Todo esto resultaría factible si pudiéramos extraer una verdadera etnografía del aquelarre, obviamente se trata de una etnografía inventada o fingida, resultado de las elucubraciones eruditas de la época en torno al diablo y su secta, la iglesia diabólica así como la práctica de sus execramentos ${ }^{10}$. Nunca se dieron los aquelarres tal y como los expresa la brujomanía de los siglos XVI y XVII, por lo que no podemos hablar más que de una etnografía sugerida por los intelectuales de la época y asumida con rapidez por las clases populares.

\footnotetext{
${ }^{8}$ Idénticas predilecciones culinarias caníbales presentan las brujas de Cartagena de Indias (1633).

9 El fenómeno del canibalismo supone uno de los episodios repulsivos empleados con asiduidad en la historia de la humanidad para justificar habitualmente el bestialismo del "Otro". Así sucede en el imaginario de la época para los comensales del aquelarre, pero también se aplicó a judíos, cristianos y a los movimientos heréticos en diferentes momentos de la historia (Cohn 1997). Igualmente fue utilizado en el ámbito colonial americano para explicar la barbarie indígena y justificar su conquista (Jáuregui 2008).

${ }^{10}$ Este modelo, el de la iglesia diabólica y el ejercicio de "misas negras" en el desarrollo del aquelarre y sus nociones inversas con respecto a la iglesia cristiana mediante la práctica de execramentos, aparece recogido en la obra de Fray Martín de Castañega [1529] y será retomado en relación a las prácticas rituales indígenas en el Nuevo Mundo por el jesuita Acosta [1590] en los Andes y por el franciscano Andrés de Olmos [1553] en la Nueva España, conocido de Castañega con quien colaboró en España. Para una valoración del modelo de inversión que con respecto a la iglesia católica y su liturgia supone el aquelarre, ver Tausiet (2012).
} 
No hay unanimidad sobre el resultado final del banquete, para unos sabroso en extremo, para otros nauseabundo. El banquete nefando propiciado por el diablo en el aquelarre, acrecienta el valor de su ambigüedad: sabroso y exquisito o repugnante e inmundo. Tal es así que las viandas se comportan como si fueran excrementos provocando su rápida expulsión, renunciando a su naturaleza alimenticia puesto que provocan largas indigestiones, no se asimilan y se evacúan con rapidez.

Phelipe de Vizcancho, de hedad de 40 años, no 44, fol. 19, dize que quando cenaua carne humana en el aquelarre, de la que desenterraban, le hazia grande daño, y otro dia de mañana trocaua unas cosas muy hediondas, y que a su pareçer, si no lo hiziera, rebentara. Maria Ansorena, de hedad de 70 años, $n^{-}$55, fol. 6, dize que quando cenaban en el aquelarre carne de bruxos difuntos, que desenterraban, le hazia mucho daño por ser esta asquerosa. Y unas bezes, luego que llegaua a casa, y otras, por la mañana otro dia, trocaua lo que auia cenado en el aquelarre y todo aquel dia se hallaua movida y con mala disposición (Idoate 1972: 135).

En realidad no se trata de verdadera comida sino que, fruto de la actuación diabólica que cambia de materia y sustancia los dones que ofrece a sus seguidores, es trocada por un símil nauseabundo que no llena, incapaz de saciar y nutrir como hace la verdadera comida. Así lo manifiesta Flores Arroyuelo:

Después de la danza y la orgía se inicia el banquete compuesto generalmente de carne de caballo, queso, manteca... y otras pitanzas. También falta la sal y el pan, símbolos gratos a Dios. La comida es una exaltación de Satanás "creador de todas las cosas" y se desarrolla en medio de un estrépito ensordecedor. Pero aquellas son más aparentes que otra cosa, ya que no tienen sabor o son detestables, haciendo que los allí reunidos salgan tan hambrientos como al principio (Flores Arroyuelo 1976: 122-123).

No sólo no alimenta, sino que el simple recuerdo de sus componentes es incompatible con el apetito, provocando ascos y arcadas los días sucesivos, así como la sensación indigesta de ocupación estomacal, lo que a la postre se constituye en ayuno satánico.

Joanes de Sansinena, de hedad de 20 años, $n^{\circ}$ 9, fol. 50, dize que las çenas del aquelarre le sabian bien quando çenaban pan, queso y cebolla, y bebían bino, / y que otro dia sintia en el estomago lo que auia çenado en el aquelarre. Y el tafo del bino y de la çeuolla, le benia a la boca y que le sustentaua, porque otro dia no thenia gana de almorzar. Martin de La Espidia, de hedad de 76 años, $n^{\circ}$ 26, fol. 10, dize como desenterrauan los cuerpos de los bruxos y los llebaban al aquelarre, y los hazian pedaços y asaban y cocian, y una parte quedaua cruda, y que comian los dichos pedaços. Y que aunque le sabia bien quando lo comia, despues le hazia mal estomago y muchas bezes lo bomitaua quando llegaua a su casa y otro dia por la mañana. Y trahia todo el dia el estomago cargado y asqueroso, y le benía a la boca el tafo de lo que auia comido y bebido. Y también comian pan y cebolla y otras cosas, y el bino que bebian no hera muy bueno. (Idoate 1972: 135).

El banquete satánico del aquelarre es un mero remedo culinario, puesto que ni las viandas, ni los hábitos en torno a la mesa son los propios de una comensalía educada. Se trata de un mero símil, un fraude ${ }^{11}$, atribuido por los eruditos de la época al "simio de dios", el diablo:

\footnotetext{
${ }^{11}$ La comida y la bebida del aquelarre muestra algún rasgo distintivo con respecto a la comida ordinaria; el aspecto es similar, pero no su sabor. "Martin de la Espidia, de hedad de 76 años, no 26, fol. 10, dize [...] Y que el bino, aunque en la color parezia a lo de Nauarra, no thenia tan buen sabor como lo que se vende en las tabernas" (Idoate 1972:138).
} 
Si alguien quiere echar mano de las carnes de valor, no encontrará ningún cuerpo sólido, únicamente aire, y solamente se pueden alcanzar esas carnes asquerosas que no se pueden comer sin sentir horror. Son carnes falsas, falsos cocineros y falsos sirvientes, y su pan es una desagradable torta negra hecha con mijo negro y con alguna droga, con la que engatusan a los niños, que nunca se sientan en la mesa y obligan a comer prácticamente a la fuerza, pegándoles incluso, como varios nos han confesado, porque no querían comer. Y para engañar mejor a los niños y a los que justo comienzan a asistir a esos festines - pues los niños que cuidan de los sapos son únicamente espectadores- el Diablo quiere que los brujos simulen que están comiendo, que rumien como los bueyes y muevan la mandíbula como si efectivamente estuviesen comiendo (Lancre 2004: 166).

La comida del aquelarre resulta desabrida porque habitualmente no se condimenta con sal. La comida insípida, sin sabor, acrecienta el sentido anómalo de la culinaria del aquelarre desde la perspectiva cultural ordinaria ${ }^{12}$. El hecho de que las viandas se elaboren sin sal, tiene una gran importancia en el discurso atribuido a las brujas. Pierre de Lancre (2004: 166, 167) relaciona la sal con el bautismo y con el cristianismo, de tal forma que su ausencia propicia el gusto de la secta diabólica. El que la comida no tenga sal aleja a sus comensales del comer cristiano, al igual que otros elementos lingüísticos asociados al cristianismo como decir "Jesús", nombrar a la "Virgen" o similares rompen el clímax del aquelarre y hacen volver todo a la realidad habitual. Por otra parte, la sal es responsable de la articulación de las viandas en la comida, comer por tanto con sal es un rasgo aglutinante de la cultura normativa de la que los comensales en el aquelarre carecen. La sal es un producto que contribuye en gran medida a que los alimentos no sólo adquieran sabor, sino que perseveren tiempo sin corromperse, especialmente la carne cruda. La carne servida en el aquelarre es corrupta por su naturaleza humana cadavérica, ya sea fruto de la necrofagia tras el desentierro y desmembramiento de brujos y brujas adultos difuntos, así como igualmente en el caso de niños muy pequeños generalmente sin bautizar $^{13}$. La propia presencia de Satanás acrecienta la idea corruptible de las viandas puesto que su figura adolece siempre de un atractivo especial por lo nauseabundo que impregna su propio aroma corporal. La comida del aquelarre, putrefacta, es incompatible con la cualidad preservadora de la sal. La sal libra temporalmente a los alimentos de la corrupción, lo mismo que la sal del bautismo preserva a los fieles del pecado. Sólo los niños sin bautizar, a los que no se les ha

\footnotetext{
${ }^{12}$ La comida y su forma de elaboración constituye un marcador cultural de carácter excepcional sobre los acontecimientos humanos. En algunas circunstancias excepcionales es preciso que la comida no esté acondicionada, sea insípida o se evite el picante, caso de las comidas y banquetes funerarios en algunas culturas americanas. El carácter insípido de la comida en el aquelarre es igualmente resaltado por las brujas de Cartagena de Indias quienes identifican su textura desabrida, como si fuera "paja" (Splendiani et al. 1997).

${ }^{13}$ Otro de los hábitos que se achacaba a las brujas y brujos en sus prácticas dañinas consistía en la degustación de las esencias vitales humanas mediante usos de corte vampírico, según las creencias de la época, reflejadas en los expedientes inquisitoriales que consistían en "chupar" a los niños y niñas pequeños "por el sieso y la natura"; así se decía que les chupaban la sangre y sus esencias vitales por el sieso (el ano), la vagina, o incluso estrujándoles las sienes (Mongastón 1998: 178-179). Estos relatos ocultaban, en no pocas ocasiones, trágicas negligencias de alcoba en el cuidado de los niños más pequeños (Tausiet 1998; 2008: 343).
} 
aplicado la sal del Bautismo, son llevados al aquelarre, descuartizados e ingeridos por los brujos o bien chupados por sus orificios naturales ${ }^{14}$.

Los gráficos de Ziarkno que ilustran el libro de Pierre de Lancre muestran los diferentes episodios vividos en el aquelarre, entre ellos los banquetes nefandos con práctica de necrofagia y canibalismo, la escena produce repulsión y sugiere la ferocidad y el caos acústico propiciado por los comensales, que reproduce el sonido del infierno según algunos relatos de la época:

A veces la imagen del infierno que tienen estas recuerda los cuadros del Bosco. La madrileña sor Mariana Francisca de los Ángeles (1637-97), carmelita descalza, bajó al infierno en visión y según su biógrafo, fray Alonso de la Madre de Dios, en un voluminoso libro publicado en 1736, afirmaba que sintió que le metieron la cabeza en un bonete de fuego, por las narices humos de azufre, en la boca una gran piedra, que sacaban los demonios con furia. "Había en el [infierno] un alboroto horrendo. Tocaban unos tambores y chirimías tan roncas y destempladas que no hay palabras que lo puedan explicar. Hacíanse hogueras y luminarias con piedra azufre, que daban una lumbre muy oscura y un humo hediondísimo" (Caro Baroja 1985: 79).

Nada sobra del banquete; al finalizar hay que llevarse los restos a casa lo que era especial competencia de la Reina del aquelarre:

Graziana de Barrenechea, de hedad de 80 años, $\mathrm{n}^{\circ}$ 7, fol. 80, madre de la preçedente, contesta con ella y dize que llebaba a su casa lo que sobraba en el aquelarre de la cena, asi la carne de los difuntos como el pan y bino, y lo demas que sobraua, porque le perteneçia por su oficio de Reyna. Y que en su casa lo comia y conbidaua a otras bruxas amigas (Idoate 1972: 137).

\section{SECUELAS AMERICANAS DEL PROCESO DE ZUGARRAMURDI}

La presencia de "juntas" y conciliábulos de brujas bajo el patrocinio del diablo, a la manera del Pirineo "vasco navarro", aparece registrada en algunas de las crónicas de indias, expedientes inquisitoriales y procesos de extirpación de idolatrías de la América colonial. La culminación del Concilio de Trento (1545-1563) y la aplicación de las políticas resultantes en ambas orillas del Atlántico, condenando los "excesos" en las formas externas de fe y tratando de reconducir las expresiones populares de culto, da lugar a la localización de formas heterodoxas e idolátricas de culto, tanto en Europa, como en América que serán, para el caso de españoles, criollos y negros, objeto de indagación por parte de los tribunales del Santo Oficio por lo que afectaba a la posibilidad de incurrir en herejía, no así en el caso de los indios que no podían ser encausados por la inquisición, tras el decreto de Felipe II que los calificaba como infieles «nuevos en la fe" y a los que se aplicó, en algunos casos y espacios concretos, los tribunales de extirpación de la idolatría, como en la Sierra de Lima, en períodos sucesivos a lo largo

\footnotetext{
${ }^{14}$ Los cuerpos de los niños bautizados que eran desenterrados por los brujos no parecen propios para el consumo antropofágico, como si la sal del bautismo los preservara y "contaminara" en su pureza haciéndolos inapropiados para su consumo caníbal; sin embargo, sí son empleados en la elaboración de pócimas y ponzoñas, así como "hachas" o cirios a la manera de luminarias demoníacas con sus extremidades superiores (Lancre 2004: 167).
} 
del siglo XVII. Es así cómo los casos de brujería, hechicería y otras creencias heterodoxas están recogidas en los procedimientos inquisitoriales y en los expedientes de extirpación de idolatrías, dependiendo de las poblaciones afectadas.

La referencia a las brujas de Zugarramurdi en el dominio colonial americano, a veces textual, es empleada como baremo de escala que el cronista utiliza para expresar la relevancia de los acontecimientos que describe; es decir se usa como referencia de "autoridad" para ejemplificar la significación de la epidemia de brujería que se pretende denunciar. En ocasiones Zugarramurdi aparece de forma simplemente nominativa, mientras que los hechos descritos apenas recuerdan, de lejos, algún componente del complejo aquelarre vasco navarro. Lo más frecuente es que aparezca descrito algún episodio o motivo presente en el modelo pirenaico como testimonio de su vinculación umbilical, al menos en la cabeza y mentalidad del cronista más que en los hechos descritos, con respecto a dicho complejo de brujería. Son frecuentes en los documentos próximos a la fecha del auto de fe de Zugarramurdi, alusiones a las brujas vascas y al proceso de Logroño como referentes comparativos con respecto a lo que se quiere denunciar en tierras americanas. Es el caso de las manifestaciones de los obispos de Panamá y de la Habana quienes solicitan la intervención de la inquisición de Cartagena de Indias, de cuya jurisdicción dependen en materia de brujos, tal y como recoge José Toribio Medina (1899). En este sentido, el obispo de la Habana cita a las brujas de Logroño y Vizcaya como ejemplo para destacar la importancia que adquiere la brujería en sus dominios:

No cumpliera con mi oficio, escribía por su parte, el de Cuba al Consejo, si no diera cuenta
de las cosas que pasan en este mi obispado, que como la isla tiene trescientas leguas de
longitud y en toda ella hay muchos lugares y mucha frecuentación de gente española,
mulatos y mestizos que de ordinario han vivido licenciosamente, y los prelados antiguos,
temerosos de las perniciosas conciencias desta gente, se habían floja y remisamente en
el castigo de los delitos que cometían contra nuestra santa fe católica por los muchos
testimonios que les levantaban, y aunque después acá los tribunales del Santo Oficio, así
de México como el nuevo proveído en Cartagena han nombrado comisarios religiosos ...
no fueron personas de satisfacción porque usaban mal de sus comisiones. Pero lo que
más sobresaltado traía á este prelado, como al de Panamá, era la infinidad de brujas y
hechiceras que allí pululaban, "pues no sé, expresaba, que en toda la tierra de Logroño y
Vizcaya haya tantas" (Medina 1899: 116-117).

El caso de Zugarramurdi aparece mencionado incluso textualmente en el dominio colonial americano en fechas cercanas al célebre auto de fe, siempre con la intención de señalar la importancia que, según el criterio del cronista, adquiere la brujería y sus manifestaciones en el lugar que describe. Un ejemplo particularmente expresivo de este hecho lo encontramos en la Sierra de Lima, en pleno proceso de extirpación de idolatrías ${ }^{15}$, en la relación escrita por el jesuita Luis Teruel en 1617. La relación procede de una visita de idolatrías, escena que sitúa en un pueblo de la costa peruana a $120 \mathrm{~km}$ de Lima, que recoge el cronista agustino Antonio de la Calancha en su Corónica moralizada.... Tomo la descripción de Pierre Duviols:

\footnotetext{
15 Podemos considerar la extirpación de idolatrías como un modelo ideológico, político y religioso que utilizando la retórica, pretende la correcta evangelización de los indios y la reprobación y eliminación de sus pautas ceremoniales paganas a principios del Siglo XVII, tanto en Nueva España, como en la Sierra de Lima, en el Virreinato del Perú (Urbano 2011).
} 
Los brujos de la Barranca tenían sus juntas como las del aquelarre de tierra de Burgos en el pueblo de Cegarramurde [leer Zugarramurdi] porque en un cerrillo ${ }^{16}$ que cae sobre el mar, i tiene en lo alto una buena plaçuela, se juntavan todos ellos i allí se les mostraba el Demonio en figura de león, perro, cabrón i en otras, i juntos los brujos los reprendía de que rezavan i ablavan en español ${ }^{17} \mathrm{i}$ de que eran amigos de los españoles sus enemigos ${ }^{18}$. El que quería vengarse de alguno, allí le pedía le ayudase i el Demonio les mandavan traer la sangre de tal que ellos le sacavan chupando el sieso $^{19}$ i la llevavan al Demonio que la convertía en carne aparente i allí cozida o $\operatorname{asada}^{20}$ se la dava a comer al que se quería vengar i con aquello solo sin frío ni calentura se consumía i moría el otro en el tiempo que el brujo quería. Acabada la junta el Demonio les mandava se mezclasen carnalmente en su presencia y lo azían ora cayesen onbres con onbres ora mugeres con mugeres, padre con ija o ermano con ermana; por fin de todo el Demonio alçava la cola y todos le besavan ${ }^{21}$. Confesó uno destos que no siendo brujo se untó 22 i se allava en las juntas i que era de tan infernal sabor la sangre que chupada convertía el Demonio en aparente carne que les azia trocar asta echar del pecho i entrañas vivas su propia sangre i los indios comprobaron esto con que vían a estos brujos y brujas estar seis i diez oras arrojando flujo de sangre del asco i orror que les causava la del que moría (Duviols 1977: 32-33).

Motivos inspirados en los aquelarres pirenaicos aparecen en la documentación colonial americana, en ocasiones mezclados con las propias manifestaciones rituales de los grupos aborígenes locales. Los expedientes por idolatrías nos ofrecen, entre otros motivos, una información detallada sobre ciertas costumbres rituales, ceremoniales, prácticas de hechicería y manifestaciones de cultos heterodoxos que hubieran sido de conocimiento de los tribunales de la Suprema, de no ser los indígenas nuevos en la predicación.

\footnotetext{
${ }^{16}$ Si bien existen montañas en la tradición vasco-navarra que son consideradas lugares específicos de reunión de brujas, en el caso de los Andes, las "plazuelas de los cerros" adquieren una nueva relevancia y dimensión cultural como lugar predilecto en donde se realizan rituales y ceremonias.

${ }^{17}$ Empleando la retórica y el exemplum a modo de relato convincente, el "demonio-huaca" se revela enemigo acérrimo de los españoles, los defensores del evangelio. El discurso semeja en parte las revelaciones y denuncias de los taquioncoys tal y como acredita la crónica de Molina [1575] y las Informaciones de Cristóbal de Albornoz [1577].

${ }^{18}$ Los "brujos", en masculino, hechiceros y dogmatizadores del relato del jesuita, se emparentan con las "brujas" (en femenino) herejes del proceso de Zugarramurdi.

${ }^{19}$ Recordemos cómo las brujas en el imaginario peninsular español eran expertas "chupadoras" de niños pequeños fundamentalmente, de los que se decía que les chupaban la sangre y sus esencias vitales por el sieso (el ano), la vagina, o incluso estrujándoles las sienes (Tausiet 2008: 339-364). Este modelo que pudiéramos definir como "vampírico" aparece tanto en las versiones andinas como en las caribeñas del aquelarre americano, por influjo de los propios cronistas, fiscales e inquisidores.

${ }^{20}$ Hemos visto anteriormente cómo el consumo de carne humana en los aquelarres de Zugarramurdi se dividía en tres partes que se consumían, según el relato de Mongastón, tanto cruda, como asada y cocida. Esta diferenciación culinaria pasa igualmente a los aquelarres americanos y se hace especialmente expresa en el caso de las brujas de Cartagena y Tolú (1633) (Splendiani et al. 1997).

${ }^{21}$ Todos ellos constituyen episodios prestados del modelo del aquelarre peninsular.

${ }^{22}$ El uso de ungüentos para alcanzar el lugar del aquelarre constituyó materia de conflicto y polémica entre los crédulos y los escépticos en materia de brujería en el proceso de Zugarramurdi. La búsqueda de los ungüentos constituyó una verdadera obsesión pericial dando lugar a no pocos fraudes clamorosos como documenta el inquisidor Salazar y Frías en su visita a los lugares implicados en el proceso de las brujas de Zugarramurdi y Urdax, después de efectuado el lamentable auto de fe de noviembre de 1610 (Henningsen 2004).
} 
En este sentido, así como los expedientes inquisitoriales constituyen una base detallada de información sobre los delitos de brujería y hechicería tanto de mestizos, españoles como afroamericanos, no sucede lo mismo para el caso de los indios, puesto que no fueron objeto de estas pesquisas inquisitoriales, por más que la suprema tuvo la tentación en varias ocasiones de levantar esta prohibición, por los tratamientos heterodoxos habituales de los indios en sus prácticas de fe y, en el caso de los Andes, por el consumo de la hoja de coca (Sánchez 1997:139-162). Por ello, para el caso indígena de los siglos XVII y XVIII, las visitas de idolatrías constituyen un material histórico, casi etnográfico podríamos decir, de primer nivel que nos ayuda a subsanar esta laguna metodológica como complemento de los expedientes inquisitoriales en el dominio colonial americano.

A buen seguro, tras las recomendaciones que la Suprema establece en materia de brujería, una vez resuelto el caso de Zugarramurdi (1614) en todo su dominio jurisdiccional, incluyendo los territorios americanos y Sicilia, no eran ajenos a sus caracteres y peculiaridades los altos cargos eclesiásticos responsables de su ejecución. Paradójicamente, junto a estas disposiciones de prudencia, sensatez y escepticismo sobre los hechos de brujería que emana del Consejo de la Suprema Inquisición, brotan igualmente las formas sardónicas del "retablo diabólico" con sus juntas de brujas en sus manifestaciones más crédulas, con sus componentes nefandos y embelesos criminales, compartiendo sobre dichos actos inauditos, dudas, recelos, credulidades y desconfianzas a partes iguales.

El peso específico del "caso Zugarramurdi" en materia de brujería parece suficientemente relevante para la época; su modelo se tomó como expresión cualificada en el análisis de los supuestos fenómenos de brujería producidos en aquellos territorios de Ultramar bajo jurisdicción de la Suprema. En este sentido podemos afirmar que fue la Suprema, a través de sus admoniciones, resultado del proceso de Zugarramurdi, quien contribuyó a la extensión del modelo en tierras americanas, al menos en un primer momento, tanto o más que las propias creencias de los emigrantes vascos en América o las aportaciones etnográficas de la brujería africana debida al comercio infame de esclavos o las propias referencias indígenas, tradiciones, todas ellas, con las que terminó hibridándose dicho modelo con el paso del tiempo. El ejemplo de las brujas de Tolú y Cartagena de Indias, expuestas a la condena pública en el Auto de Fe celebrado en Cartagena de Indias en marzo de 1633, resulta paradigmático en este sentido ${ }^{23}$.

En las crónicas de Indias, el diablo aparece forjado por el imaginario español asociado a las prácticas rituales y formas de culto indígenas en un proceso de diabolización que se concreta en todo el ámbito colonial (Cervantes 1995; Sánchez 2007; Fernández Juárez 2012). Es así cómo el diablo aparece bajo la forma de cabrón encabezando las juntas o reuniones de los brujos y brujas que en el dominio europeo configuran un motivo de larga tradición recurrente a lo largo de su historia, como es el aquelarre, cuyos componentes integradores (canibalismo, homicidio, transformismo animal, procacidad sexual, maleficios, banquetes nefandos, adoración al diablo, etc.) han servido

\footnotetext{
${ }^{23}$ Sobre las secuelas del proceso de Zugarramurdi en el auto de fe de las brujas de Cartagena y Tolú de 1633 he realizado un estudio específico que verá pronto la luz en la Revista Internacional de Estudios Vascos.
} 
sistemáticamente para deslegitimar al otro, adaptando sus manifestaciones sensibles de forma excepcional al ámbito americano (Cañizares-Esguerra 2008; Federici 2010).

Por lo que se refiere al dominio culinario, en las formas del aquelarre americano en tiempos coloniales, destacaríamos junto con el vampirismo infantili24, otras modalidades de canibalismo utilizando el levantamiento de figura o un avatar del infortunado, como expresa el ejemplo de los Andes que hemos visto anteriormente, remedando al propio Zugarramurdi. La vinculación entre la torta nefanda sangrienta y la ingesta del alma del infortunado describe acertadamente, en términos etnográficos contemporáneos, la estrecha relación existente entre el cuerpo y las entidades anímicas que configuran el concepto de "ser humano" en numerosas culturas amerindias (Gutiérrez Estévez 2010). En los Andes, encontramos algunos ejemplos de prácticas de hechicería que pretenden la ingesta del "alma" como forma precisa para fulminar a la víctima. Devorar su "alma", es decir, la pluralidad de entidades anímicas que constituyen la naturaleza humana en cada caso, comporta la garantía simbólica de su destrucción ${ }^{25}$.

\section{EL MUNDO AL REVÉS}

¿Qué podemos sacar en claro de las prácticas culinarias desarrolladas en las juntas y conventículos de brujos que tanto los eruditos de la época como las clases populares no dudaban en achacarles?

Los aquelarres expresan de forma amplificada aspectos contrarios e inversos al hecho cultural humano. Justifican la máxima expresión del bestialismo asociado a colectivos en exclusión o que pudieran competir en algún sentido con los representantes hegemónicos de la sociedad (Cohn 1997). La inversión que el aquelarre supone, no sólo se produce con respecto al ejercicio de la misa católica y los sacramentos cristianos (Tausiet 2012), sino con respecto a las dimensiones sociales y culturales precisas en la vida en comunidad. Las formas del aquelarre pirenaico, a ambos lados de la frontera vasco navarra en España y Francia, incorporan manifestaciones culinarias, pero también festivas, musicales y de orden sexual que describen este "mundo invertido".

En la cualidad festiva del aquelarre y su sentido inverso con respecto a los bailes de comunidad destacarían las danzas acrobáticas en círculo de sentido levógiro y dándose los participantes la espalda, tal y como describe Ziarnko en su grabado (Iriondo 2010: 173-174). Los bailes acrobáticos y en círculo desarrollado por la izquier$\mathrm{da}^{26}$, fueron descritos por Pierre de Lancre (2004) como propios de los vascos, a quie-

${ }^{24}$ Descrito con todo detalle en las Cartas Annuas de los jesuitas (Polia 1999) por lo que se refiere a los Andes peruanos, en 1621, y presente así mismo en las descripciones sobre los crímenes atribuidos a las encausadas por brujería en Cartagena de Indias (1633).

${ }^{25}$ En el Altiplano aymara subiste este género de "devorador de almas" que no hace sino utilizar el símil contrario a lo que es la resolución terapéutica más habitual en este espacio cultural y caracterizado por la restitución y sanación de las entidades anímicas extraviadas (Fernández Juárez 1995).

${ }^{26}$ Idoate (1972: 76) identifica estas danzas como karrikadantzas, propias del ámbito "Vasconavarro". Aparece reflejado igualmente en los documentos de Alonso de Salazar y Frías para el caso de Zugarramurdi (Henningsen 2004). 
nes entroncaba directamente como pueblo de Satanás por los caracteres de su lengua y algunos de sus hábitos culturales. En relación a las danzas en círculo tenemos algunas referencias del caso de Zugarramurdi:

Mariana de Tornariarena, de hedad de 60 años, letra A, fol 13, dize que una tarde, por el mes de septiembre anteçedente, estando en su casa, vino a ella una mujer bieja, vezina suya, y le dixo que fuese con ella al molino, donde tenia una su hija. Y esta lo hizo y se fueron juntas a boca de noche, y pasando por una llano, sintieron sonido como de tamborin, que lo hazian para dançar o vailar. Y aunque esta es corta de vista, echo de uer que auia alli muchas personas reboçadas de negro y de blanco, con que traian tapadas las caras, y se entretenian y rregucijauan. Y que un bezino suyo, que nombro, cantaua al son del tamborino un cantar muy suzio en basquençe, que esta declaro en rromance». Y que esta entro tambien en la dança que hazian, asidos de las manos, y andando en rrueda, como se acostumbra en aquella tierra". Y de la una mano, lleuaua la dicha bieja, su vezina, y de la otra, no saue quien la asio, mas de que continuando el baile, a los primeros pasos la apreto mucho de la mano, de suerte que le causo dolor. Y esta, sintiéndose dello y del dicho cantar tan desonesto, dixo: jJesus! ¿Quien me aprieta? Y en diziendo esto la dexaron de ambas manos, y a su parecer, segun la poca vista que tenia, entendio que todos se abian desaparecido, porque no bio ni oyo mas las dichas personas ni ruido, antes se ubo de boluer sola, tropeçando y cayendo hasta su casa. Y otro dia siguiente, se quexo a la dicha su vezina, culpandola de la auer lleuado a tan mala parte y amenazandola que si otra bez la lleuaua, la auia de afrentar en la yglesia y diría lo que hauia pasado. Y la dicha bieja la rrespondio: ¿Pues yo, que mal os e hecho? Yo os dexare de aqui adelante. Y esta, nunca otra bez auia visto ni bio la dicha junta (Idoate 1972: 76-77).

La construcción erudita del retablo de Ziarnko en el libro de Pierre de Lancre, muestra en el baile a los participantes, brujas y diablos intercalados entre sí, en disposición incómoda en círculo y uniendo sus manos por la espalda, evitando así la mirada frontal que permite la integración social de la danza.

La música descrita en los expedientes inquisitoriales alude a la característica de las fiestas populares de la zona con una marcada preferencia instrumental por flautas y tamboriles generalmente, pero también rabeles y gaitas en algunos casos, muy lejos, por tanto, de la música erudita, "de cámara", que aparece reflejada en el grabado de Ziarnsko como aparente remedo de los propios ministriles catedralicios (Martínez Gil 2000). Los testimonios inciden en el carácter ambiguo de la música del aquelarre, para unos desentonada, como el canto que acompaña el desarrollo de las misas negras, para otros, reflejo de una armonía sublime y sutil. Esta ambigüedad propia del perfil mítico que adquiere el demonio en la época, acrecienta el sentido provocador y temido de la música, tanto en la expresión sensible de los instrumentos empleados como en el resultado de su expresión estética, capaz de tentar con su seducción a sabios y santos (Vernant 2001) ${ }^{27}$.

Los datos sobre relaciones sexuales atribuidos a brujas y brujos en el desarrollo de los aquelarres, resultan en ocasiones muy descriptivos y explícitos. El pormenor de la información quizá nos dice más sobre las obsesiones de los jueces, fiscales e inquisidores y sus elaboraciones intelectuales que sobre los propios protagonistas encausados. Encontramos de nuevo en los relatos expresiones de índole heterogénea

\footnotetext{
${ }^{27}$ Agradezco encarecidamente los comentarios de los doctores Sara González Castrejón (Berwick University of London) y Fernando Martínez Gil (Universidad de Castilla-La Mancha) sobre la música de los aquelarres.
} 
y ambigua sobre la experiencia emocional asociada a dichas supuestas relaciones. Para unos las relaciones sexuales mantenidas con el demonio en el aquelarre resultan agradables y comparables a las emociones sexuales sentidas entre hombres y mujeres, sin embargo en la mayor parte de las informaciones, las relaciones sexuales no son placenteras, de hecho son dolorosas, contra natura y con efusión de sangre, especialmente en el caso de los brujos.

Miguel de Goyburu, de hedad de 60 años, $\mathrm{n}^{\circ}$ 8, fol. 56, dize que quando el demonio le conocio la primera vez someticamente, le salio sangre, y quando fue a casa y a otro dia, lo echo de uer en la camisa. Joanes de Goyburu, de hedad de 37 años, no 10, fol. 60, dize que quando el demonio tubo acesso con el, le salio sangre, y que otro dia la hallo en la camisa. Martin de Vizcar, de hedad de 70 años, $n^{\circ}$ 11, fol. 7, dize que el demonio le estupro y saco grande cantidad de sangre, que le corria por los muslos y le ensangrento mucha parte de la camisa. Y quando su muger la vio llena de sangre, le dixo que de donde diablo trahia la camisa de aquella manera, y el le rrespondio que se auia dado un encuentro en la pierna. Maria de Dindarte, de hedad de 40 años, $\mathrm{n}^{\mathrm{o}} 32$, fol. 7 , dize que la primera bez que el demonio le conocio someticamente, tubo mucho dolor y le salio sangre, y otro dia la echo de uer en la camisa (Idoate 1972: 141).

Importante a efecto de nuestro análisis es la práctica habitual del incesto entre los miembros del aquelarre, los relatos indican claramente que no se respeta condición alguna, ni de género (hombres con hombres, mujeres con mujeres) ni de parentesco (hijos con madres, hermanos con hermanos). Canibalismo e incesto son dos conceptos que han aparecido sistemáticamente relacionados como marcadores culturales de la bestialidad a lo largo de la historia.

Las expresiones corporales sobre la imagen del demonio coinciden en destacar su mal olor, la frialdad de su carne y un miembro que resulta, en ocasiones, excepcionalmente grande y duro mientras que en otras es pequeño y flácido, es decir poco propicio para el goce en las relaciones sexuales. Por otro lado, las profundas discusiones eruditas de teólogos y sesudos doctores de la Iglesia sobre el semen del diablo y su capacidad de procrear, fueron muy habituales en la época moderna; baste recordar el célebre Malleus Maleficarum (1486). Las brujas vasco navarras suelen resaltar o bien la falta de esperma del diablo o su carácter excesivamente frío. Las brujas de Cartagena de Indias y de Tolú, encausadas en 1633, destacaban de forma extrema el carácter cálido o muy frío del semen del diablo, en cualquier caso incompatible con la procreación.

Entre los indios americanos y los afrodescendientes protagonistas de los aquelarres coloniales, el bestialismo que generan las mentes eruditas de los cronistas en su distanciamiento frente al "otro", indio o negro, se expresa no sólo por lo que describen en sus comidas con un criterio caníbal exacerbado y nada etnográfico, sino también por sus danzas frenéticas y la obscenidad de sus relaciones sexuales (Horswell 2010; Amodio 2012). Es curioso reflejar la homosexualidad latente y el bestialismo aplicado a las relaciones sexuales que no hacen sino incidir en la representación femenina de América, y la lascivia de las mujeres indígenas o afrodescendientes, sólo comparable a la voracidad de su apetito caníbal, como acreditan los falsos mitos en torno al canibalismo indígena que los relatos coloniales europeos han configurado (Arens 1981) ${ }^{28}$.

${ }^{28}$ El coqueteo de la antropología con el canibalismo indígena es conocido desde los inicios de la disciplina, menos proclive a reconocer a los propios caníbales en el ámbito occidental, afron- 
El "aquelarre" o "Sabbat" propicia una valoración moral de los cronistas europeos sobre los pueblos amerindios en razón de sus pretendidas prácticas diabólicas (antropofagia, homicidios, procacidad sexual, banquetes nefandos, "borracheras", transformismo animal, vuelos nocturnos y ungüentos, etc.) que se daban en el aquelarre, según la proyección del aquelarre europeo sobre los rituales indígenas. Probablemente sea la referencia erudita al pacto diabólico que se aplicaba a las brujas el gozne de unión entre herejes e idólatras que redundará más tarde en la diabolización de los ritos y creencias indígenas. Las mentalidades, ofuscaciones y manías de los jueces, fiscales, inquisidores y visitadores de las idolatrías, aparecen plasmadas en sus propias expresiones sensibles sobre los conventículos de brujas, más que en las versiones de los encausados; circunstancia que análogamente sucede en los expedientes inquisitoriales de la Peninsula Ibérica. Las prácticas ceremoniales indígenas y su proceso de diabolización colonial, al igual que había ocurrido con los hábitos religiosos heterodoxos de los campesinos ibéricos y europeos (Caro Baroja 1961: 71-75) propician la mirada anti idolátrica de los visitadores sobre los cultos indígenas. El entramado festivo, el consumo de alcohol y sustancias alucinógenas, propias de los avatares rituales de los pueblos amerindios, adquieren forma diabólica en las versiones americanas sobre los aquelarres.

La sociedad del aquelarre es una comunidad culinaria que determina un espacio gastronómico concreto ${ }^{29}$ a través de su tendencia al canibalismo y la elaboración peculiar de sus viandas. Dicho espacio culinario está configurado por lazos de pertenencia entre los comensales que comparten obligaciones derivadas del consumo común:

[...] Nunca se come un niño entero en un sabbat que se realice en una sóla parroquia, y este niño que ella vio que llevaban y troceaban en un Sabbat de Ciboure. Lo cortaron en cuatro partes, una de las cuales se comió en Ciboure, mientras las tres restantes las llevaron a otras parroquias. Dijo asimismo que todos los niños que pueden robar de esta forma son conducidos al Sabbat sin Bautismo, y una vez allí los descuartizan y comen (Lancre 2004: 167).

En definitiva, la comida de los aquelarres define un cuadro asocial externo a ellos, marcado por la inversión de valores sociales con respecto a la gastronomía habitual: la comida no es tal en realidad, no produce trama ni relaciones sociales externas al espacio del aquelarre y su comunidad. Sus viandas son desabridas, no se condimentan, no tienen sal ni sabor, su textura es similar a la paja, no sacian y producen hambruna por cuanto no alimentan y someten al comensal a una involución digestiva que concluye con su vómito, produciendo como efecto inmediato un ayuno y abstinencia forzada durante varias jornadas e insufribles molestias estomacales. En

tando en la actualidad nuevos y seductores perfiles sobre dicho concepto, asociados al capitalismo voraz, el tráfico de órganos o las manifestaciones artísticas postmodernas (López García 2009; Jaúregui 2008; Federici 2010).

${ }^{29}$ En palabras de Jesús Contreras: «Un cierto número de indicadores gustativos afirman una identidad alimentaria, delimitan muy vigorosamente la pertenencia culinaria a un territorio determinado, como es el caso, por ejemplo, del uso de una grasa determinada para cocinar: el aceite de oliva en el mediodía mediterráneo y la manteca de cerdo o la mantequilla en el oeste delimitan una auténtica 'frontera gastronómica' y, en esa misma medida cultural" (Contreras 1992: 102). 
cuanto a la elaboración es confusa (crudo, asado, cocido), lejos del orden y de la limpieza exigida en los banquetes sociales, confusión marcada por la disposición de las viandas en los manteles y la algarabía sonora que refleja desorden, caos, en definitiva contaminación y suciedad (Douglas 1991). Ese mundo bestial que los eruditos de los siglos XVI y XVII no dudaban en atribuir a los brujos, al igual que anteriormente otros habían encarnado ese escenario muy a su pesar, encuentra entre los indios americanos y esclavos negros, apropiado acomodo en plena eclosión del proceso colonial americano. La comida sirve como marcador cultural definitorio entre lo social y lo asocial, el orden y el caos, lo católico y lo satánico, la ortodoxia y la herejía, lo humano y lo bestial, discriminando, de forma contundente, las cualidades humanas de aquellas otras impropias o contrarias a su propia naturaleza.

\section{BIBLIOGRAFÍA CITADA}

Acosta, J. de. 1954 [1590]. Historia Natural y Moral de las Indias. Obras del Padre José de Acosta. Madrid: BAE.

Albornoz, C. de. 1990 [1557]. "Información de servicios, Cuzco 1577", en Millones, L. (comp.), El retorno de las huacas: 167-201. Lima: IEP.

Amodio, E. 2012. "El detestable pecado nefando. Diversidad sexual y control inquisitorial en Venezuela durante el Siglo XVIII" Nuevo Mundo Mundos Nuevos [En línea] (Puesto en línea el 11 julio 2012, consultado el 28 diciembre 2012). http://nuevomundo.revues.org/63177; DOI: 10.4000/ nuevomundo.63177

Arens, W. 1981. El mito del canibalismo. Antropología y Antropofagia. México: Siglo XXI.

Azurmendi, M. 2012. "A vueltas con el término aquelarre". Cuadernos, 9. Revista Internacional de Estudios Vascos: 43-53.

Cañizares-Esguerra, J. 2008. Católicos y puritanos en la colonización de América, Madrid: Marcial Pons.

Caro Baroja, J. 1961. Las brujas y su mundo, Madrid: Revista de Occidente.

Caro Baroja, J. 1975. Brujería vasca. San Sebastián: Txertoa.

Caro Baroja, J. 1985. Las formas complejas de la vida religiosa (Siglos XVI y XVII). Madrid: Sharpe.

Castañega, M. de. 1994 [1529]. Tratado de las supersticiones y hechizerias y de la posibilidad y remedio dellas. Logroño: Instituto de Estudios Riojanos,

Cervantes, F. 1995. El diablo en el Nuevo Mundo. El impacto del diabolismo a través de la colonización de Hispanoamérica. Barcelona: Herder.

Cohn, N. 1997 [1976]. Los demonios familiares de Europa. Barcelona: Altaya.

Contreras. J. 1992. "Alimentación y cultura: Reflexiones desde la Antropología". Revista Chilena de Antropología 11: 95-111.

Douglas, M. 1991. Pureza y peligro. Un análisis de los conceptos de contaminación y tabú. Madrid: Siglo XXI.

Duviols, P. 1977. La destrucción de las religiones andinas (Durante la Conquista y la Colonia). México: Universidad Nacional Autónoma de México.

Federici, S. 2010. Calibán y la bruja. Mujeres, cuerpo y acumulación originaria. Madrid: Traficantes de Sueños.

Fernández Juárez, G. 1995. El banquete aymara. Mesas y yatiris. La Paz: Hisbol.

Fernández Juárez, G. 2012. Hechiceros y Ministros del Diablo. Quito: Abya-Yala..

Fernández Nieto, M. 1989. Proceso a la brujería. En torno al auto de fe de las brujos de Zugarramurdi. Logroño 1610. Madrid: Tecnos.

Flores Arroyuelo, F. J. 1976. El diablo y los españoles. Murcia: Universidad de Murcia.

Ginzburg, C. 2003 [1989]. Historia nocturna. Las raices antropológicas del relato. Barcelona: Península. 
Ginzburg, C. 2011 [1966]. Els Benandanti. Bruixeria $i$ cultes agraris al ssegles XVI $i$ XVII. Valencia: Universitat de València.

Gutiérrez Estévez, M. 2010. "Esos cuerpos, esas almas. Una introducción", en Gutiérrez, M. y Pitarch, P. (eds.), Retóricas del cuerpo amerindio: 9-55. Madrid: Iberoamericana.

Henningsen, G. 1983. El abogado de las brujas. Madrid: Alianza Editorial.

Henningsen, G. (ed.). 2004. The Salazar Documents. Inquisitor Alonso de Salazar and Others on the Basque Witch Persecution. Leiden, Boston: Brill.

Henningsen, G. 2010. "La Brujomanía vasca", en Ramalle, E. y Azurmendi, M. (eds.), Inquisición y brujería. El auto de fe de Logroño de 1610: 19-32. Logroño: Instituto de Estudios Riojanos.

Henningsen, G, 2012. "El invento de la palabra aquelarre». Cuadernos, 9 Revista Internacional de Estudios Vascos : 55-66.

Horswell, M. J. 2010. La descolonización del "sodomita" en los Andes coloniales. Quito: Abya-Yala.

Idoate, F, 1972. Un documento de la inquisición sobre brujería en Navarra. Pamplona: Aranzadi.

Iriondo, M. 2010. "Imágenes de la brujería. De la literatura a la imagen y de la imagen al estereotipo narrativo", en Ramalle, E. y Azurmendi, M. (eds.), Inquisición y brujería. El auto de fe de Logroño de 1610: 131-197. Logroño: Instituto de Estudios Riojanos.

Jaúregui, C. A. 2008. Canibalia. Canibalismo, calibanismo, antropología cultural y consumo en América Latina. Madrid: Iberoamericana.

Lancre, P. de. 2004 [1612]. Tratado de Brujería vasca. Descripción de la Inconstancia de los Malos Ángeles o Demonios. Tafalla: Txalaparta.

Levack, B. P. 1995. La caza de brujas en la Europa Moderna. Madrid: Alianza Editorial.

López García, J. 2009. “Canibalismo siglo XXI. La actualidad popular de una vieja preocupación antropológica”. Revista de Dialectología y Tradiciones Populares LXIV (1): 95-132.

Marcos Casquero, M. A. y Riesco Álvarez, H. B. 1997. Pedro de Valencia. Obras Completas, VII. Discurso acerca de los cuentos de las brujas. León: Universidad de León.

Martínez Gil, C. 2000. "Los sonidos de la fiesta: Música y ceremonial en el Corpus Christi", en Fernández Juárez, G. y Martínez Gil, F. (coords), La fiesta del Corpus Christi: 215-234. Cuenca: Servicio de Publicaciones de la UCLM.

Medina, J. T. 1899. Historia del Tribunal del Santo Oficio de la Inquisición de Cartagena de las Indias. Santiago de Chile: Imprenta Gutemberg.

Molina, C. 2008 [1575]. Relación de las fábulas y ritos de los incas. Lima: Universidad San Martín de Porres.

Mongastón, J. de. 1998 [1611]. Relación de las personas que salieron al auto de la fe. Logroño: Edición de Manuel de las Rivas.

Murray, M. 1978 [1921]. El culto de la brujería en Europa Occidental. Barcelona: Labor.

Olmos, A. de. 1990 [1533]. Tratado de hechicerias y sortilegios. México: UNAM.

Polia, M. 1999. La cosmovisión religiosa andina en los documentos inéditos del Archivo Romano de la Compañía de Jesús, 1581 1752. Lima: Pontificia Universidad Católica del Perú.

Ramalle Gómara, E. y Azurmendi Inchausti, M. (eds.). 2010. Inquisición y brujería. El auto de fe de Logroño de 1610. Logroño: Instituto de Estudios Riojanos.

Sánchez, A. 1997. "El talismán del diablo'. La Inquisición frente al consumo de coca. (Lima, siglo XVII)». Revista de la Inquisición 6: 139-162.

Sánchez, J. 2007. "La imposición del diabolismo cristiano en América". Cuadernos del Minotauro 5: 23-47.

Splendiani, A. M. et al. 1997. Cincuenta años de Inquisición en el Tribunal de Cartagena de Indias 1610-1660. Santa Fé de Bogotá: Pontificia Universidad Javeriana.

Sprenger, J. e Institoris, E. 2004 [1486]. El martillo de las brujas. Para golpear a las brujas y sus herejias con poderosa maza. Malleus Maleficarum. Valladolid: Maxtor.

Tausiet, M. 1998. "Brujería y metáfora: El infanticidio y sus traducciones en Aragón (ss. XVI-XVII)". Temas de Antropología Aragonesa 8: 61-84.

Tausiet, M. 2008. "Por el sieso y la natura. Una lectura literaria de los procesos por brujería". Edad de Oro XXVII: 339-364.

Tausiet, M. 2012. "Brujería y eucaristía. El aquelarre como antivisión". Cuadernos, 9. Revista Internacional de Estudios Vascos: 66-89. 
Urbano. H. 2011. "Pablo Joseph de Arriaga S J. Retórica y extirpación de idolatrías en el Arzobispado de Lima (Siglos XVI-XVII)", en Izquierdo, R. y Martínez, F. (coords), Religión y heterodoxias en el Mundo Hispánico. Siglos XIV-XVIII: 153-170. Madrid: Sílex.

Usunáriz, J. M. (ed.). 2012. Akelarre: la caza de brujas en el Pirineo (siglos XIII-XIX). Cuadernos, 9. Revista Internacional de Estudios Vascos. San Sebastián: Eusko Ikaskuntza.

Vernant, J. P. 2001. La muerte en los ojos. Figuras del Otro en la antigua Grecia. Barcelona: Gedisa.

Fecha de recepción: 19 de enero de 2014

Fecha de aprobación: 8 de abril de 2014 